\title{
Fotossíntese, condutância estomática e potencial hídrico foliar em árvores jovens de andiroba (Carapa guianensis)
}

\author{
Gracilene Fernandes da COSTA ${ }^{1}$, Ricardo A. MARENCO ${ }^{2}$ \\ RESUMO \\ O potencial hídrico da folha é um dos fatores mais importantes que afetam o funcionamento dos estômatos. O objetivo deste \\ trabalho foi avaliar o efeito da variação diurna na irradiância e déficit de pressão de vapor (DPV) na fotossíntese $(A)$, condutância \\ estomática $(\mathrm{g}$ ) e potencial hídrico da folha $(\Psi)$ em Carapa guianensis (Aubl.). Os dados foram coletados de 07:00 às 17:00 h. A taxa \\ fotossintética atingiu um valor máximo $\left(2,5 \mu \mathrm{mol} \mathrm{m}^{-2} \mathrm{~s}^{-1}\right)$ às 10:00 h, depois declinou até atingir um mínimo de $1 \mu \mathrm{molm}^{-2} \mathrm{~s}^{-1}$ às \\ 16:00 h. A condutância estomática oscilou durante o dia, de $0,04 \mathrm{molm}^{-2} \mathrm{~s}^{-1}$ (ao meio dia) para $0,02 \mathrm{molm}^{-2} \mathrm{~s}^{-1}$ no final da tarde. $\mathrm{O}$ \\ potencial hídrico da folha foi máximo nas primeiras horas do dia (-0,3 MPa) e mínimo (-0,75 MPa) no meio da tarde (14:30 a 15:00 \\ h). Após ter alcançado um mínimo, o $\Psi$ aumentou até -0,64 MPa no fim da tarde. A taxa fotossintética aumentou linearmente em \\ função do $g_{s}(P \leq 0,01)$. Também houve uma relação positiva entre $\Psi$ e g $(P \leq 0,01)$. A taxa fotossintética declinou durante o dia \\ após ter alcançado um pico no início da manhã, demonstrando que os fatores ambientais que afetam o $\Psi$ têm efeito significativo na \\ assimilação do carbono de C. guianensis.
}

PALAVRAS-CHAVE

Déficit de pressão de vapor, potencial hídrico foliar, transpiração, trocas gasosas da folha.

\section{Photosynthesis, stomatal conductance and leaf water potential in crabwood (Carapa guianensis)}

\section{ABSTRACT}

Leaf water potential is one of the most important factors affecting stomatal functioning. The aim of this study was to assess the effect of variation in diurnal irradiance and vapour pressure deficit on photosynthesis (A), stomatal conductance ( $g$ ) and leaf water potential $(\Psi)$ in Carapa guianensis (Aubl.). Data were collected from 07:00 to 17:00 h. Photosynthetic rates reached a maximum $\left(2.5 \mu m o l m^{-2} \mathrm{~s}^{-1}\right)$ at 10:00 h, thereafter declined to a minimum of 1 mom m $\mathrm{m}^{-2} \mathrm{~s}^{-1}$ at 16:00 h. Stomatal conductance oscillated during the day, from $0.04 \mathrm{~mol}$ $\mathrm{m}^{-2} \mathrm{~s}^{-1}$ (at midday) to 0.02. mol. $\mathrm{m}^{-2} \cdot \mathrm{s}^{-1}$ at the end of the afternoon. Leaf water potential was higher early in the morning (-0.3 MPa) and lower (-0.75 MPa) at mid-afternoon (14:30-15:00 h). After reaching a minimum, $\Psi$ increased up to -0.64 MPa at sunset. Photosynthetic rates increased linearly as a function of $g_{s}(P \leq 0.01)$. Also there was a positive relationship between $\Psi$ and $g_{s}(P \leq 0.01)$. Photosynthetic rates declined during the day after reaching a peak early in the morning, which makes clear that environmental factors that influence $\Psi$ greatly affect carbon assimilation of $\mathrm{C}$. guianensis.

\section{KEYWORDS}

Leaf gas exchange, leaf water potential, transpiration, vapour pressure deficit.

${ }^{1}$ Eng. Florestal. Bolsista da Fundação de Amparo à Pesquisa do Estado do Amazonas (FAPEAM) no âmbito do Projeto FAPEAM/PIPT 1084-04. e-mail: lenyfernandes@hotmail.com 2Eng. Agrônomo, Doutor. Pesquisador Associado, Instituto Nacional de Pesquisas da Amazônia, INPA-CPST. e-mail: rmarenco@inpa.gov.br 


\section{INTRODUÇÃO}

A andiroba (Carapa guianensis Aubl.) é uma árvore de dossel que pode atingir mais de $30 \mathrm{~m}$ de altura, apresenta sapopemas baixas, tronco reto e cilíndrico e folhas compostas. Ocorre em toda a bacia amazônica, nas matas de várzea ou em regiōes alagadiças dos rios. A andiroba é uma espécie que apresenta uma cornucópia de benefícios às populaçôes locais da Amazônia, devido a sua grande utilidade na indústria madeireira, seu valor ecológico e propriedades medicinais do óleo extraído das suas sementes. Dentre outras propriedades, o óleo de andiroba serve como antiinflamatório. A madeira da andiroba é moderadamente pesada $\left(0,73 \mathrm{~g} \cdot \mathrm{cm}^{-3}\right)$, usada na construção de móveis, pisos, compensados e acabamentos internos de barcos e navios; floresce em agosto-setembro e janeiro-fevereiro e tudo indica que seja polinizada por insetos; os frutos amadurecem em junho-julho e fevereiro-março (Lorenzi, 1992).

A intensidade luminosa, a temperatura, a concentração de $\mathrm{CO}_{2}$, o teor de nitrogênio da folha e a umidade do solo são fatores que afetam a atividade fotossintética dos vegetais (Marenco \& Lopes, 2005). O processo de abertura e fechamento dos estômatos está relacionado principalmente com a intensidade de luz e o estado de hidratação da folha. Dessa forma, o funcionamento dos estômatos e a área foliar influenciam a produtividade do vegetal. O primeiro fator porque controla a absorção de $\mathrm{CO}_{2}$ e o segundo porque determina a interceptação de luz.

O potencial de água da folha indica o seu estado energético, cujos gradientes explicam os fluxos da água no sistema soloplanta-atmosfera (Bergonci et al., 2000) de modo que, variações no potencial hídrico da folha podem afetar a assimilação do carbono da planta (Hsiao, 1973). Isto porque, se a planta perde água a uma taxa superior à sua capacidade de absorção e transporte o potencial hídrico da folha diminui, levando ao fechamento dos estômatos e redução da fotossíntese. Presume-se que nos horários mais quentes do dia a condutância estomática diminua a ponto de evitar que o potencial hídrico da folha desça abaixo de níveis considerados críticos para a estabilidade do sistema de transporte de água (Oren et al., 1999). O nível mínimo que o potencial hídrico pode atingir durante os horários de transpiração intensa depende tanto de fatores genéticos como de fatores ambientais (p. exe., pré-aclimatação a situação de estresse). Contudo, em situação de baixa disponibilidade de água no solo as plantas reduzem a perda de água ao reduzir a condutância estomática. Para favorecer a turgescência celular em situações de estresse hídrico, ocorrem ajustes no metabolismo celular, por exemplo, via o acúmulo de substâncias orgânicas, tais como a prolina, o que contribui para a osmorregulação (Silva et al., 2004).

Segundo Larcher (2000), a capacidade fotossintética é uma característica intrínseca de cada espécie vegetal, sendo que as trocas gasosas mudam durante o ciclo do desenvolvimento do indivíduo e dependem do curso anual e até mesmo do curso diário das flutuações ambientais (luz, temperatura, etc) em torno do vegetal. Em plantas jovens de Cupania vernalis (Camb.), uma espécie arbórea, Lima-Junior et al. (2005) observaram altas taxas de fotossíntese e condutância estomática em folhas crescidas sob pleno sol. Em plantas jovens de Stryphnodendron adstringens (Mart.) a fotossíntese é nula quando o potencial hídrico da folha cai para -2,7 MPa, (Rocha \& Morais, 1997), o que mostra o forte efeito do estado de hidratação da folha na assimilação do carbono.

Devido à escassez de estudos envolvendo a ecofisiologia da andiroba, o objetivo deste trabalho foi avaliar o efeito da variação diurna na irradiância e déficit de pressão de vapor na fotossíntese $(A)$, condutância estomática $\left(\mathrm{g}_{\mathrm{s}}\right)$ e no potencial hídrico de folhas ( $\Psi)$ dessa espécie.

\section{MATERIAL E MÉTODOS}

O presente estudo foi realizado no campus do Instituto Nacional de Pesquisas da Amazônia (INPA) em Manaus, AM (lat. $03^{\circ} 05^{\prime} 30^{\prime \prime} \mathrm{S}$; long. 59 59' 35" O). A cidade de Manaus apresenta características de clima equatorial úmido, com temperatura média de $27{ }^{\circ} \mathrm{C}$, variando de $23{ }^{\circ} \mathrm{C}$ a $32^{\circ} \mathrm{C}$, precipitação anual de 2240 (média 1961-1990) e umidade relativa de $78 \%$ (Inmet, 2006). Foram utilizadas folhas maduras e completamente expandidas de árvores de andiroba (Carapa guianensis Aubl., Meliaceae) de $6 \mathrm{~m}$ de altura, que ainda não tinham iniciado o processo reprodutivo. Os dados foram coletados em dezembro de 2005 e janeiro de 2006, período no qual a umidade do solo permanece sempre próxima à capacidade de campo, devido às chuvas freqüentes.

As taxas de fotossíntese $(A)$ e a condutância estomática $\left(\mathrm{g}_{\mathrm{s}}\right)$ foram medidas com um analisador de gás infravermelho $(\mathrm{Li}-$ 6400, Li-Cor, Lincoln, EUA) em folhas de três árvores de andiroba. A concentração de $\mathrm{CO}_{2}$ dentro da câmara, a irradiância, a umidade do ar e a temperatura oscilaram conforme as condiçôes do ambiente. Os dados foram coletados das 7:00 às 17:00 h em intervalos de três minutos, para um total de 200 observações por dia. A irradiância foi medida utilizando um sensor quântico ( $\mathrm{Li}$ 190 SA, Li-Cor, EUA) conectado a um datalogger em intervalos de 15 minutos.

O potencial hídrico da folha $(\Psi)$ foi medido com sensores psicrométricos (L-51, Wescor, Utah, EUA) conectados a um datalogger. As medições foram realizadas a intervalos de dez minutos, das 7:00 às 17:00 h nas mesmas plantas utilizadas para as mensurações da fotossíntese. No total foram instalados cinco sensores psicrométricos por planta. A relação entre $A$ e g e entre $\mathrm{g}_{\mathrm{s}}$ e foi analisada mediante regressão. Além disso, foram construídos gráficos mostrando a variação de $\mathrm{A}, \mathrm{g}_{\mathrm{s}}, \mathrm{e} \Psi \mathrm{em}$ função do horário do dia, tendo-se como parâmetro de comparação o erro padrão da média. 


\section{RESULTADOS E DISCUSSÃO}

A radiação fotossinteticamente ativa (RFA) oscilou durante o dia devido à nebulosidade do ambiente, atingindo valores máximos próximos de $2000 \mu \mathrm{mol} \mathrm{m}^{-2} \mathrm{~s}^{-1}$. Devido a problemas técnicos no datalogger unicamente os dias 12 e 13 de janeiro foram registrados (Figura 1A). O déficit de pressão de vapor da folha (DPV) aumentou gradativamente ao longo dia, acompanhando os aumentos da temperatura da folha $\left(\mathrm{T}_{\mathrm{F}}\right)$ (Figura 1B, C). Pode-se observar na Figura 1B, que a variação no DPV refletiu estreitamente as mudanças em $T_{F}$ pelo fato de $o$ DPV ser uma variável que depende tanto da umidade e temperatura do ar como da temperatura da folha (Marenco \& Lopes, 2005).

A fotossíntese $(A)$ aumentou rapidamente com a irradiância atingindo o valor máximo de $2,5 \mu_{\mathrm{molm}}^{-2} \mathrm{~s}^{-1}$ às 10:00 h; depois declinou até valores próximos de 1,5 $\mu \mathrm{mol} \mathrm{m}^{-2} \mathrm{~s}^{-1}$ entre 14:00 e

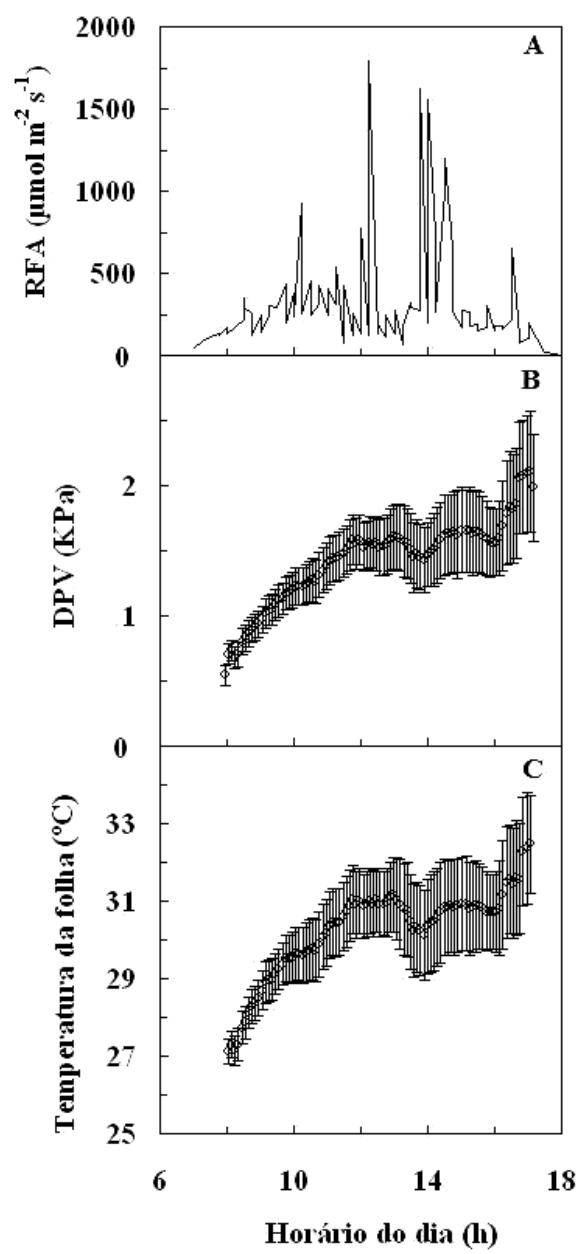

Figura 1 - Curso diurno da radiação fotossinteticamente ativa (RFA) a céu aberto (dias 12 e 13 janeiro, 2006), déficit de pressão de vapor da folha (DPV) e temperatura da folha de $C$. guianensis em função da hora do dia. Em B e C cada símbolo representa a média de três plantas ( $\pm \mathrm{SE})$.
14:45 h, sendo mínima ao final da tarde quando a radiação solar foi muito baixa (Figura 2A). Os valores de condutância estomática oscilaram na faixa de 0,03 e $0,04 \mathrm{molm}^{-2} \mathrm{~s}^{-1}$, diminuindo gradativamente durante o dia, chegando a atingir $0,02 \mathrm{molm}^{-2} \mathrm{~s}^{-1}$ ou menos após às 16:00 h (Figura 2B). Em relação aos valores do potencial hídrico da folha, encontrou-se que o $\Psi$ decresceu desde o amanhecer até atingir um mínimo de -0,75 MPa entre 14:30 e 15:00 h. Foi observado também que, no final da tarde, o potencial hídrico da folha mostrou uma clara tendência de acréscimo, sendo de -0,64 MPa ao pôr-do-sol. Essa tendência provavelmente continuou durante a noite, pois ao amanhecer o potencial hídrico da folha foi sempre máximo (em torno de -0,3 MPa) (Figura 2C).

A queda da fotossíntese nos horários do meio dia pode ser atribuída à fotoinibição (Dias \& Marenco, 2006) ou à redução da condutância estomática (Dias \& Marenco, 2007). A primeira

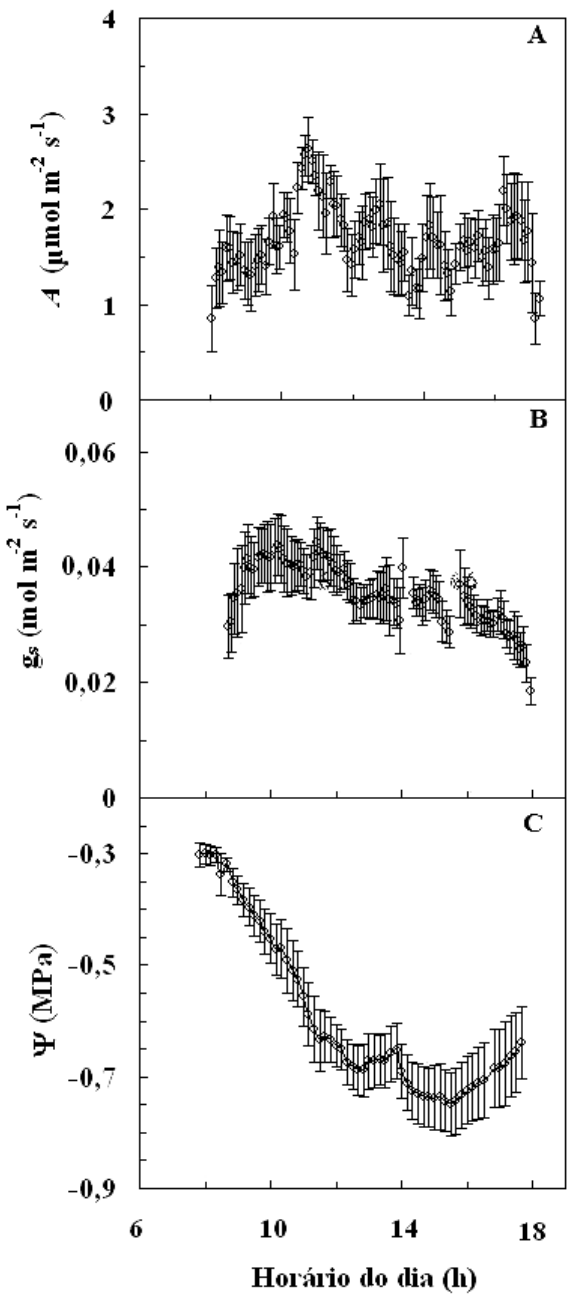

Figura 2 - Fotossíntese $(A, A)$, condutância estomática $\left(g_{s}\right.$, B) e potencial hídrico da folha $(\Psi, C)$ em $C$. guianensis em função da hora do dia. Cada símbolo representa a média de três plantas $( \pm \mathrm{SE})$. 
hipótese não parece provável porque a irradiância observada durante a maior parte do dia (menos de $1000 \mu \mathrm{molm}^{-2} \mathrm{~s}^{-1}$ ) foi menor do que a requerida para saturar a fotossíntese em espécies de crescimento rápido aclimatadas ao sol, tais como Swietenia macrophylla (King.) (Marenco et al., 2001a), Ochroma pyramidale (Urban.) (Marenco et al., 2001b) e Cedrela odorata (L.) (Maruyama et al., 2005). Deste modo, a queda na condutância estomática parece ser a causa mais provável da redução da fotossíntese nos horários do meio dia. Com relação à variação diurna os resultados desta pesquisa são semelhantes aos encontrados nas folhas de laranjeira "Valência" (Citrus sinensis L.), onde foi observado que a taxa de fotossíntese no mês de janeiro foi maior no período da manhã do que na parte da tarde (Machado et al., 2002). Analogamente, em Guazuma ulmifolia (Lam.) e Croton spp, espécies pioneiras, os valores de fotossíntese são também maiores nas primeiras horas da manhã (Ribeiro $e t$ al., 2005).

A queda da condutância estomática ao longo do dia pode ser atribuída ao aumento do DPV, à diminuição do potencial hídrico da folha ou ao efeito combinado de ambos fatores, sem excluir o efeito da irradiância. Com relação aos efeitos do $\Psi$ e DPV, ainda não é claro se a condutância estomática é mais responsiva ao potencial hídrico da folha ( $\Psi$-atuando como um mecanismo de retroalimentação ou feedback) ou se $\mathrm{g}_{\mathrm{s}}$ responde mais rapidamente à variação na umidade do ar (que determina o DPV) como um mecanismo de resposta antecipada (feedforward), para evitar a perda excessiva de água (Raschke, 1979). Com relação às oscilaçōes diurnas em $\mathrm{g}_{\mathrm{s}}$, estas variações estão de acordo com Passos et al. (2005) que em Cocus nucifera (L.) observaram que os valores de $\mathrm{g}_{\mathrm{s}}$ foram maiores nos horários da manhã, o que sugere um efeito do potencial hídrico na condutância estomática. Os resultados deste trabalho concordam com os relatados por Ferreira et al. (1999) que, em Eucalyptus citriodora (Hook), observaram que os maiores valores de condutância estomática ocorrem quando a radiação solar é máxima e o potencial hídrico da folha ainda não atingiu os valores mínimos passíveis de induzir o fechamento estomático. Paralelamente, Cascardo et al. (1993) também constataram que a condutância estomática da seringueira (Hevea brasiliensis Muell.) é máxima quando o teor de água da folha é alto, o que ocorre nas primeiras horas da manhã, quando a folha não perdeu muita água por transpiração.

A variação diurna do potencial hídrico observado neste estudo é similar à relatada por outros pesquisadores (Perez \& Morais, 1991; Naves-Barbiero et al., 2000; Jadoski et al., 2005). Por exemplo, em Erytroxylum suberosum (St.) os valores de $\Psi$ diminuem até atingir um mínimo próximo das 14:00 h, observando-se reidratação da folha ao final da tarde (Perez \& Morais, 1991). Também em Rapanea guianensis (Lam.) e Roupala montana (Aubl.) o potencial hídrico da folha é máximo pela manhã, mas diminui até atingir valores mínimos entre 13:00 e 15:00 h, aumentando a turgidez da folha ao final da tarde (Naves-Barbiero et al., 2000).

A correlação entre potencial hídrico $(\Psi)$ e $g_{s}$ foi positiva e altamente significativa, porém relativamente baixa $(\mathrm{r}=0,27)$ (Figura 3A). Uma relação similar também foi observada entre a taxa de fotossíntese $(A)$ e condutância estomática $\left(\mathrm{g}_{\mathrm{s}}\right.$ ) (Figura 3B). A baixa correlação entre $A$ e g e entre g e $\Psi$ confirma que tanto a fotossíntese como a condutância estomática são parâmetros da planta que respondem simultaneamente a um conjunto de fatores que interagem de forma coordenada, mas altamente complexa. Enquanto, a baixa concentração de $\mathrm{CO}_{2} \mathrm{e}$ a alta irradiância estimulam diretamente a abertura dos estômatos, a baixa umidade e a transpiração excessiva causam diminuição no potencial hídrico foliar, o que pode levar ao fechamento dos estômatos (Hsiao, 1973; Marenco et al., 2006). Desse modo, não é surpreendente encontrar uma baixa correlação entre $A$ e g s em condiçôes naturais de luminosidade e umidade do ar. Além disso, uma pobre correlação entre fotossíntese e condutância estomática pode indicar ausência de uniformidade na abertura dos estômatos na superfície da folha (manchas estomáticas), conforme mostrado por Marenco et al. (2006), tornando complexa e não linear a relação entre fotossíntese e condutância estomática (Pospisilová \& Santrucek, 1994).

Finalmente, deve-se mencionar que embora $C$. guianensis seja uma espécie de crescimento rápido, as taxas de fotossíntese em condiçôes naturais de luminosidade, concentração de $\mathrm{CO}_{2} \mathrm{e}$ umidade do ar foram relativamente baixas, se comparadas com os valores bem superiores de fotossíntese relatados para outras espécies de crescimento rápido, em condiçōes controladas de $\mathrm{CO}_{2}$ e luz saturante (Marenco et al., 2001b, Maruyama et al., 2005). Isto mostra que a taxa de crescimento de uma espécie é determinada não apenas pela capacidade de assimilação de carbono, mas por uma série de outros fatores como a taxa de respiração, a eficiência na translocação de assimilados e a superfície foliar da planta, que interagem de forma complexa, e cujo resultado final é o acumulo de biomassa (Marenco \& Lopes, 2005).

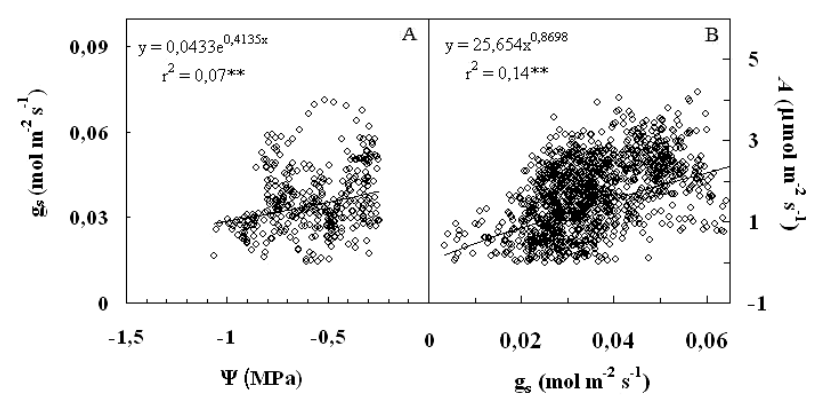

Figura 3 - Relação entre potencial hídrico da folha $(\Psi)$ e $g_{s}(A)$ e entre fotossíntese $(A)$ e condutância estomática $\left(\mathrm{g}_{\mathrm{s}}, \mathrm{B}\right)$ em $C$. guianensis. Cada ponto indica uma observação. 


\section{CONCLUSÕES}

A taxa de fotossíntese apresentou valores mais elevados no início da manhã, quando o potencial hídrico da folha é mais alto. A correlação entre condutância estomática e fotossíntese foi positiva, porém baixa, demonstrando que as respostas dos estômatos às variações na luminosidade e umidade do ar são complexas.

Observou-se uma queda acentuada no potencial hídrico foliar, ao longo do dia, refletindo as variaçóes diurnas da temperatura do ar e do DPV. Embora a andiroba seja uma espécie de crescimento rápido, apresentou baixas taxas de fotossíntese em condições naturais de luminosidade, umidade do ar e concentração de $\mathrm{CO}_{2}$, evidenciando a complexidade de fatores envolvidos no acúmulo de biomassa da planta.

\section{AGRADECIMENTOS}

Ao MCT-INPA e à Fundação de Amparo à Pesquisa do Estado do Amazonas (projeto FAPEAM - PIPT 1084-04) pelo financiamento do trabalho. Ao CNPq e a FAPEAM pelas bolsas concedidas.

\section{BIBLIOGRAFIA CITADA}

Bergonci, J.I.; Bergamaschi, H.; Berlato, M.A.; Santos, A.O. 2000. Potencial da água na folha como um indicador de déficit hídrico em milho. Pesquisa Agropecuária Brasileira, 35(8): 1531-1540.

Cascardo, J.C.M.; Oliveira, L.E.M.; Soares, A.M. 1993. Disponibilidade de água e doses de gesso agrícola nas relações hídricas da seringueira. Revista Brasileira de Fisiologia Vegetal, 5(1): 31-34.

Dias, D.P.; Marenco, R.A. 2006. Photoinhibition of photosynthesis in Minquartia guianensis and Swietenia macrophylla inferred by monitoring the initial fluorescence. Photosynthetica, 44(2): 235240.

Dias, D.P.; Marenco, R.A. 2007. Fotossíntese e fotoinibição em mogno e acariquara em função da luminosidade e temperatura foliar. Pesquisa Agropecuária Brasileira, 42(3): 305-311.

Ferreira, C.A.G.; Davide, A.C.; Carvalho, L.R. 1999. Relações hídricas em mudas de Eucalyptus citriodora Hook., em tubetes, aclimatadas por tratamentos hídricos. Cerne, 5(2): 95-104.

InMet, 2006. Clima (www.inmet.gov.br/clima). Acesso: 14/08/06.

Hsiao, T.C. 1973. Plant responses to water stress. Annual Review of Plant Physiology and Plant Molecular Biology, 24: 519-570.

Jadoski, S.O.; Klar, A.E.; Salvador, E.D. 2005. Relações hídricas e fisiológicas em plantas de pimentão ao longo de um dia. Ambiência, 1(1): 11-19.

Larcher, W. 2000. Ecofisiologia Vegetal. São Carlos, São Paulo. Editora Rima, 531pp.

Lima-Junior, E.C.; Alvarenga, A.A.; Castro, E.M.; Vieira, C.V.; Oliveira, H.M. 2005. Trocas gasosas, características das folhas e crescimento de plantas jovens de Cupania vernalis Camb. submetidas a diferentes níveis de sombreamento. Ciência Rural, 35(5): 1092-1097.

Lorenzi, H. 1992. Arvores brasileiras: manual de identificação e cultivo de plantas arbóreas nativas do Brasil, Plantarum. Nova Odessa, SP. 352pp.

Machado, E.C.; Medina, C.L.; Gomes, M.M.A.; Habermann, G. 2002. Variação sazonal da fotossíntese, condutância estomática e potencial da água na folha de laranjeira 'Valência'. Scientia Agricola, 59(1): 53-58.

Marenco, R.A.; Gonçalves, J.F.C.; Vieira, G. 2001a. Leaf gas exchange and carbohydrates in tropical trees differing in successional status in two light environments in Central Amazonia. Tree Physiology, 21(18): 1311-1318.

Marenco, R.A.; Gonçalves, J.D.; Vieira, G. 2001b. Photosynthesis and leaf nutrient contents in Ochroma pyramidale (Bombacaceae). Photosynthetica, 39(4): 539-543.

Marenco, R.A.; Lopes, N.F. 2005. Fisiologia Vegetal: Fotossintese, respiração, relaçôes hidricas e nutrição mineral, Editora UFV. Viçosa, MG. 451pp.

Marenco, R.A.; Siebke, K.; Farquhar, G.D., Ball, M.C. 2006. Hydraulically based stomatal oscillations and stomatal patchiness in Gossypium hirsutum. Functional Plant Biology, 33(12): 11031113.

Maruyama, Y.; Nakamura, S.; Marenco, R.A.; Vieira, G.; Sato, A. 2005. Photosynthetic traits of seedlings of several tree species in an Amazonian forest. Tropics, 14(3) :211-219.

Naves-Barbiero, C.C.; Franco, A.C.; Bucci, S.J.; Goldstein, G. 2000. Fluxo de seiva e condutância estomática de duas espécies lenhosas sempre-verdes no campo sujo e cerradão. Revista Brasileira de Fisiologia Vegetal, 12(2): 119-134.

Oren, R.; Sperry, J.S.; Katul, G.G.; Pataki, D.E.; Ewers, B.E.; Phillips, N.; Schafer, K.V.R. 1999. Survey and synthesis of intra- and interspecific variation in stomatal sensitivity to vapour pressure deficit. Plant, Cell and Environment, 22(12): 1515-1526.

Passos, C.D.; Passos, E.E.M.; Prado, C.H.B.A. 2005. Comportamento sazonal do potencial hídrico e das trocas gasosas de quatro variedades de coqueiro-anão. Revista Brasileira de Fruticultura, 27(2): 248-254.

Perez, S.C.J.G.A.; Moraes, J.A.P.V. 1991. Determinações de potencial hídrico, condutância estomática e potencial osmótico em espécies dos estratos arbóreo, arbustivo e herbáceo de um cerradão. Revista Brasileira de Fisiologia Vegetal, 3(1): 27-37.

Pospisilová, J.; Santrucek, J. 1994. Stomatal patchiness. Biologia Plantarum, 36(4): 481-510.

Raschke, K. 1979. Movements using turgor mechanisms: Movements of stomata. In: Haupt, W.; Feinleib, M.E. (Ed.). Encyclopedia of plant physiology. Springer-Verlag. Berlin. 7: 383-441.

Ribeiro, R.V.; Souza, G.M.; Oliveira, R.F.; Machado, E. C. 2005. Photosynthetic responses of tropical tree species from different successional groups under contrasting irradiance conditions. Revista Brasileira de Botânica, 28(1): 149-161. 
Rocha, A.M.S.; Moraes, J.A.P.V. 1997. Influência do estresse hídrico sobre as trocas gasosas em plantas jovens envasadas de Stryphnodendron adstringens (Mart.). Revista Brasileira de Fisiologia Vegetal, 9(1): 41-46.

Silva, E.C.; Nogueira, R.J.M.C.; Neto, A.D.A.; Brito, J.Z.; Cabral, E.L. 2004. Aspectos ecofisiológicos de dez espécies em uma área de caatinga no município de Cabaceiras, Paraíba, Brasil. Iheringia, Série Botânica, 59(2): 201-205.

Recebido em 06/10/2006

Aceito em 10/05/2007 